\title{
SEPARAÇÃO OBRIGATÓRIA DE BENS PARA MAIORES DE SETENTA ANOS: INCOMPATIBILIDADES E INCONSTITUCIONALIDADE
}

\section{ARTIGO ORIGINAL}

TOLEDO, Maurício de ${ }^{1}$

TOLEDO, Maurício de. Separação obrigatória de bens para maiores de setenta anos: Incompatibilidades e inconstitucionalidade. Revista Científica Multidisciplinar Núcleo do Conhecimento. Ano 05, Ed. 12, Vol. 09, pp. 139-151. Dezembro de 2020. ISSN: 2448-0959, Link de acesso: https://www.nucleodoconhecimento.com.br/lei/separacao-obrigatoria

\section{RESUMO}

O presente trabalho tem por objetivo a análise da imposição do instituto da separação obrigatória de bens aos maiores de 70 (setenta) anos. Assim, abordará os motivos que levaram à criação da norma e os efeitos práticos de sua ocorrência. Além disso, tratará da patente inconstitucionalidade em controle difuso e concentrado deste regime, como consequência da sua incompatibilidade com a legislação pátria brasileira.

Palavras-chave: Separação obrigatória, inconstitucionalidade.

\section{INTRODUÇÃO}

Segundo o estudo Tábuas Completas de Mortalidade do IBGE (2018) do ano de 2017, os brasileiros têm uma expectativa de vida de 76 (setenta e seis) anos ao nascer. Esta expectativa é ainda maior se a idade base de comparação for de 65 anos, alcançando a média de 83,7 (oitenta e três anos e sete meses) anos. Logo, alguém que possua

\footnotetext{
${ }^{1}$ Acadêmico de Direito. 
esta idade hoje espera viver, no mínimo, mais 18 (dezoito) anos. A título elucidativo, conforme dados do estudo supra, a cada 1000 (mil) pessoas que completem sessenta e cinco anos, 632 (seiscentas e trinta e duas) chegarão aos oitenta anos.

Esta média ainda varia, por diversos motivos se considerarmos homens e mulheres separadamente. Além disso, pelo fato de o Brasil ser um país de dimensões continentais e possuir enormes diferenças regionais, as mais baixas expectativas de vida ainda estão acima dos 70 (setenta) anos. No primeiro caso, os homens vivem até os 72,5 anos enquanto as mulheres vivem até os 79,6 (setenta anos e seis meses) anos. Já na segunda situação, o Maranhão figura na última posição, com média de 70,9 (setenta anos e nove meses) anos, conforme dados extraídos das Tábuas Completas de Mortalidade.

Fato é que a população brasileira tem vivido muito mais nos dias atuais. Deste fato resultam inúmeros efeitos no mundo jurídico, atingindo os mais diversos campos de atuação do Direito como, por exemplo, a elaboração de políticas públicas direcionadas aos idosos ou até mesmo a preocupação com o sistema previdenciário pátrio.

Todavia, a despeito dos diversos reflexos que o envelhecimento produz nas relações jurídicas atuais, o presente trabalho tem por objetivo a reflexão acerca da adequação e dos impactos da imposição do regime de separação obrigatória de bens aos maiores de 70 (setenta) anos, à visão do ordenamento jurídico brasileiro e à luz da doutrina e jurisprudência vigentes sobre o tema.

\section{ASPECTOS GERAIS SOBRE A SEPARAÇÃO OBRIGATÓRIA}

O casamento é um dos principais temas de Direito de Família, vez que dele derivam diversos efeitos nos mais diversos institutos legais atinentes a este ramo do direito. Entre eles está o regime de bens, que será a lei patrimonial do casal na constância da união, além de ser a origem da maior parte das famílias atualmente.

Os efeitos patrimoniais do matrimônio são, de longe, os que mais geram debates e conflitos na seara judicial. Isto porque, dentre outros motivos, o legislador adota uma 
posição protetiva e concede ao Estado o poder de intervir de forma contundente no ambiente familiar em determinados casos.

Caso não exista disposição diversa pelos nubentes, o regime a ser adotado será o da comunhão parcial de bens, conforme disposição expressa do artigo 1.640 do Código Civil: "Não havendo convenção, ou sendo ela nula ou ineficaz, vigorará, quanto aos bens entre os cônjuges, o regime da comunhão parcial". Tal artigo foi um progresso em relação ao código civilista anteriormente vigente, que estabelecia a comunhão universal, não havendo manifestação de vontade em sentido contrário.

Desta maneira, foi constituído um sistema em que a vontade dos cônjuges é a regra e a lei prevê qual a regra que regerá os bens durante a constância do casamento de forma residual. Entretanto, no artigo seguinte, a regra é invertida para alguns casos específicos, in verbis:

Art. 1.641. É obrigatório o regime da separação de bens no casamento:

I - das pessoas que o contraírem com inobservância das causas suspensivas da celebração do casamento;

II - da pessoa maior de 70 (setenta) anos;

III - de todos os que dependerem, para casar, de suprimento judicial.

Em primeiro lugar, é imposto regime da separação obrigatória como uma espécie de pena, em comparação ao Direito Penal, para aqueles que se casam mesmo com a determinação legal de que não "deveriam". O fundamento de tal punição é puramente prático, vez que, se outro fosse o regime adotado, haveria confusão patrimonial e direitos de terceiros estariam potencialmente ameaçados. Logo, comprovada a inexistência de prejuízo, o juiz poderá afastar a aplicação do inciso I, a pedido dos interessados, nos termos do parágrafo único do artigo 1.523 do Código Civil:

É permitido aos nubentes solicitar ao juiz que não Ihes sejam aplicadas as causas suspensivas previstas nos incisos I, III e IV deste artigo, provando-se a inexistência de prejuízo, respectivamente, para o herdeiro, para o ex-cônjuge e para a pessoa tutelada ou curatelada; no caso do inciso II, a nubente deverá provar nascimento de filho, ou inexistência de gravidez, na fluência do prazo. 
Ademais, o Estado intervém em outra situação, quando alguém precise de suprimento judicial para o casamento. Tal determinação visa a proteção da pessoa que ainda não possui discernimento completo para dispor livremente sobre seus bens.

Por fim, a atual redação do artigo 1.641 do Código Civil de 2002 estatui que a pessoa maior de 70 (setenta) anos também deverá contrair matrimônio sob o regime da separação de bens de forma obrigatória. Desta maneira, há o estabelecimento de critério objetivo e não há a previsão de qualquer exceção liberatória, como as previstas no parágrafo único do artigo 1.523 para as causas suspensivas

Este parâmetro (setenta anos) foi inserido pela Lei n. 12.344/2010, no entanto, quando da promulgação do código em 2002, o legislador entendeu por bem estabelecer em 60 (sessenta) anos para homens e mulheres. Esta foi uma conquista em relação à disposição retrógrada do Código Civil de 1916 o qual impunha a separação de bens ao homem que se casasse com 60 (sessenta) anos e, à mulher, com 50 (cinquenta) anos.

A referida evolução foi produto direto da Constituição da República de 1988 que exclui qualquer diferenciação de pessoas pelo sexo minando qualquer argumento que tivesse esse fundamento para justificar a discriminação supra.

\section{JUSTIFICATIVAS PARA A DIFERENCIAÇÃO LEGAL}

Os fundamentos para justificar a imposição da separação obrigatória aos maiores de 70 (setenta) anos foram, até certo ponto desvirtuados, na mesma linha dos outros casos. A alegação, basicamente, foi a de que seria necessário proteger os bens destas pessoas por dois motivos, claramente equivocados.

Primeiramente, esta proteção seria direcionada, em primeiro plano, aos bens dos que já atingiram a velhice. Em caráter secundário, ao futuro (e incerto) direito dos herdeiros a estes bens tendo em vista a suposta proximidade com a abertura da sucessão.

Por outro lado, o outro argumento, ainda mais desacertado, seria o de que os idosos (sentido amplo) seriam mais suscetíveis a um relacionamento unicamente pautado 
por interesses econômicos (e escusos), o que é amplamente difundido como o "golpe do baú". A seguir, serão analisadas de forma aprofundada estas justificativas e os devidos contrapontos serão apresentados para fomentar a discussão acerca desse tema.

O fundamento de que seria necessário proteger eventuais direitos de herdeiros é claramente contra o ordenamento jurídico como um todo, não só o civilista, e por conta disso esta alegação não será minuciosamente contraposta.

Aduz o artigo 1.857 do Código Civil que qualquer pessoa capaz pode dispor, ainda em vida, de seus bens para depois de sua morte por meio de testamento e, caso esta pessoa possua herdeiros necessários a legítima será preservada, ipsis literis:

Art. 1.857. Toda pessoa capaz pode dispor, por testamento, da totalidade dos seus bens, ou de parte deles, para depois de sua morte.

$\S 1^{\circ}$ A legítima dos herdeiros necessários não poderá ser incluída no testamento.

Desta maneira, aí já se vislumbra que os herdeiros não possuem qualquer direito sobre os bens da pessoa que ainda não faleceu, tendo em vista que esta pode deles dispor livremente. Ato contínuo, a ressalva da legítima tampouco constitui expectativa de direito aos herdeiros, ainda que necessários, vez que a vedação é cabível apenas para disposições post-mortem, ou para as disposições a título gratuito, nos termos do artigo 549 do Código Civil: "Nula é também a doação quanto à parte que exceder à de que o doador, no momento da liberalidade, poderia dispor em testamento".

Entretanto, não há cláusula de intransmissibilidade sobre a legítima, podendo ainda a pessoa capaz dispor da maneira que lhe aprouver, excetuando-se a doação.

A título exemplificativo: Pedro, aposentado, conta com 75 (setenta e cinco) anos de idade e possui dois filhos. Seu único bem é um imóvel. Em plena capacidade de seus atos, vende o imóvel a um terceiro por $\mathrm{R} \$ 300.000,00$ (trezentos mil reais) e, com o valor recebido, viaja para Las Vegas, mundialmente conhecida pelas casas de jogos. Ao chegar lá, gasta todo o dinheiro jogando poker. 
Nesta situação, não há qualquer proibição legal para os atos praticados por Pedro, pois ele é capaz e pode alienar seu imóvel, viajar para os EUA (onde jogos são legalizados) e gastar da forma que bem entender, sem que seus herdeiros possam fazer alguma coisa para proteger a suposta legítima.

Sendo assim, passa-se à análise do argumento de que o maior de 70 (setenta) anos estaria suscetível ao chamado "golpe do baú" e suas várias implicações. O Código Civil Brasileiro optou por estatuir que a capacidade civil plena é adquirida aos 18 (dezoito) anos, em regra. No entanto, não há qualquer disposição legal de que esta capacidade civil tenha prazo de duração e com setenta anos seja diminuída.

Dizer que o septuagenário não pode livremente escolher o regime patrimonial caso opte por casar é o mesmo que tolher-Ihe a capacidade civil adquirida aos 18 (dezoito) anos sem qualquer motivo, a não ser o de já ter vivido por 70 (setenta) anos. Por este raciocínio, o legislador prevê que quando do septuagésimo aniversário o idoso é terrivelmente acometido por certa demência senil ou síndrome da senilidade que o transforma em um idiota para o casamento.

O absurdo acima é a única conclusão possível produzida pela premissa imposta pelo artigo 1.641, inciso II do Código Civil e está equivocada em inúmeros aspectos. Em primeiro lugar, é incorreto afirmar que essas pessoas estariam mais frágeis para constituírem relacionamentos amorosos e que ficariam cegas para as intenções das outras pessoas.

Neste sentido, a lei generaliza e considera que todas as pessoas que se relacionarem com maiores de 70 (setenta) anos estariam interessados em seu patrimônio, o que é ilegal e antiético, pois não é plausível determinar o comportamento humano de forma indeterminada pautando-se apenas por um critério, no caso, o econômico.

Além disso, esta generalização desconsidera a possiblidade, novamente, de o idoso fazer suas próprias escolhas e considera que ele estaria sendo enganado sempre que fosse se envolver amorosamente com alguém. Tal afirmativa não coaduna com a realidade, pois razoável seria que uma pessoa que já vivenciou inúmeras experiências 
durante a vida, boas e ruins, tivesse mais esclarecimento e possibilidade de tomar decisões mais acertadas do que alguém que tenha acabado de completar 18 (dezoito) anos e esteja "perdidamente apaixonado" por uma pessoa que esteja inteiramente interessada em sua possível fortuna, vez que não são apenas os mais velhos que possuem bens.

Outrossim, qual seria o grande problema de permitir que o ancião, ciente do interesse patrimonial da outra parte, escolha, espontaneamente, viver com esta pessoa e com ela dividir os bens que possui. Assim como não é possível presumir o comportamento de todos os seres humanos, também não é possível impor única conduta, ao belprazer do legislador, a todos que estiverem em certa situação da vida.

\section{INCOERÊNCIAS}

Diversas são as contradições legais do artigo acima que exigiriam uma pesquisa específica para tanto, no entanto destacam-se as seguintes situações.

Na seara política, o eleitor maior de 70 (setenta) anos tem o voto facultativo. Logo, se quiser, pode participar ativamente da escolha de seus representantes. Por analogia, este pode também ser candidato a qualquer cargo eletivo, podendo chegar ao mais alto escalão de decisões do Poder Executivo, a Presidência da República, e influenciar diretamente na vida de mais de 200 (duzentos) milhões de pessoas por meio de decretos, sanções, vetos, políticas públicas, projetos de lei de iniciativa privativa dentre outras situações, mas não pode escolher o regime patrimonial de seu casamento.

Por conseguinte, no âmbito do Poder Judiciário, os ministros do Supremo Tribunal Federal, mais alta corte judicial brasileira, possuem a garantia constitucional da vitaliciedade. No entanto devem se aposentar de forma compulsória aos 75 (setenta e cinco) anos. Desta maneira, o ministro possui aptidão para julgar e decidir questões que vincularão a atuação jurisdicional, como são os casos de repercussão geral, mas não pode escolher o regime de bens que regulará seu matrimônio. 
Por fim, nos atos da vida privada, como já mencionado anteriormente, não há qualquer vedação para realização de atos negociais, por exemplo. Portanto, é plenamente possível que um septuagenário que seja presidente de uma grande empresa celebre contratos milionários com altos riscos, porém, reforça-se, caso queira se casar não terá a possibilidade de eleger o regime de bens.

\section{ASPECTOS CONCRETOS}

\subsection{INTERDIÇÃO E ESTATUTO DO IDOSO}

Embora a generalização presumida do artigo 1.641, inciso II do Código Civil seja equivocada, conforme esclarecido acima, há casos em que há uma certa limitação da capacidade civil da pessoa maior de 70 (setenta) anos, mas não pelo fato de ter atingido esta idade e sim por se enquadrar em algumas das hipóteses de incapacidade relativa do artigo $4^{\circ}$ do mesmo diploma legal:

Art. $4^{\circ}$ São incapazes, relativamente a certos atos ou à maneira de os exercer:

I - os maiores de dezesseis e menores de dezoito anos;

II - os ébrios habituais e os viciados em tóxico;

III - aqueles que, por causa transitória ou permanente, não puderem exprimir sua vontade;

IV - os pródigos.

Para estas situações específicas, se o idoso for pródigo por exemplo, será necessário o ajuizamento de processo de interdição em que o magistrado irá analisar o caso concreto e, se entender cabível, nomeará curador para os atos da vida civil. Cessando a causa de interdição, a curatela já não será mais necessária e a pessoa voltará a ter plena capacidade civil, nos termos do artigo 1.767 do Código Civil:

Art. 1.767. Estão sujeitos a curatela:

I - aqueles que, por causa transitória ou permanente, não puderem exprimir sua vontade; 


$$
\begin{aligned}
& \text { II - (Revogado); } \\
& \text { III - os ébrios habituais e os viciados em tóxico; } \\
& \text { IV - (Revogado); } \\
& \text { V - os pródigos. }
\end{aligned}
$$

Desta maneira, duas conclusões são retiradas deste instituto: primeiro que é imprescindível que a interdição seja determinada judicialmente; e, além disso, a curatela é temporária e será extinta quando sua causa já não mais existir.

Além disso, o curador tem a função de assistir o curatelado em alguns atos da vida civil e não o substituir por completo. Sendo assim, se for possível que este possa manifestar sua vontade para contrair matrimônio, não há impedimento de que isto ocorra, vez que os relativamente capazes podem casar-se.

No mesmo sentido é a principiologia do Estatuto do Idoso, inserido no ordenamento jurídico pátrio pela Lei n. 10.741 de $1^{\circ}$ de outubro de 2003 , o qual põe a salvo os direitos fundamentais dos maiores de 60 (sessenta) anos. Ademais, a norma supra institui que o direito ao envelhecimento é personalíssimo e um direito social sua proteção.

Sendo assim, se algum idoso não for plenamente capaz, seus familiares deverão ingressar com o processo de interdição para a nomeação de curador a fim de assistilo nos atos da vida civil. Porém o ordenamento jurídico ressalva seus direitos fundamentais e sua proteção é dever de todos.

\subsection{APLICAÇÃO DA SÚMULA 377}

Ora, mesmo com os argumentos apresentados acerca da inutilidade do inciso II do artigo 1.641 da Lei Civil, a jurisprudência já flexibilizou sua aplicação nos casos de separação obrigatória, conforme disposição da súmula 377 do Supremo Tribunal Federal. 
Tal súmula, de uma forma precária, assemelhou a separação obrigatória de bens ao regime da comunhão parcial vez que instituiu a meação sobre os bens onerosos adquiridos na constância do casamento. Esta interpretação jurisprudencial visava não deixar desamparados os cônjuges em eventual dissolução do vínculo matrimonial.

Tendo em vista este entendimento sumulado da Corte Constitucional ser do ano de 1964, ele já passou por inúmeras mutações ao longo do tempo, em destaque a promulgação da Constituição Federal de 1988, bem como do Código Civil de 2002. Assim, cogita-se até mesmo a perda da sua aplicabilidade.

Entretanto, o Superior Tribunal de Justiça e os Tribunais de Justiça têm utilizado a referida súmula para efeitos de meação, de modo que o questionamento que ainda persiste é se o esforço comum deveria ou não ser presumido. Desta maneira, visando uniformizar o emprego da súmula, a Segunda Seção do STJ estabeleceu que o esforço comum deve ser comprovado, sob pena de completa desidratação do regime da separação legal de bens:

EMBARGOS DE DIVERGÊNCIA NO RECURSO ESPECIAL. DIREITO DE FAMÍLIA. UNIÃO ESTÁVEL. CASAMENTO CONTRAÍDO SOB CAUSA SUSPENSIVA. SEPARAÇÃO OBRIGATÓRIA DE BENS (CC/1916, ART. 258, II; CC/2002, ART. 1.641, II). PARTILHA. BENS ADQUIRIDOS ONEROSAMENTE. NECESSIDADE DE PROVA DO ESFORÇO COMUM. PRESSUPOSTO DA PRETENSÃO. MODERNA COMPREENSÃO DA SÚMULA 377/STF. EMBARGOS DE DIVERGÊNCIA PROVIDOS.

1. Nos moldes do art. 1.641, II, do Código Civil de 2002, ao casamento contraído sob causa suspensiva, impõe-se o regime da separação obrigatória de bens.

2. No regime de separação legal de bens, comunicam-se os adquiridos na constância do casamento, desde que comprovado o esforço comum para sua aquisição.

3. Releitura da antiga Súmula 377/STF (No regime de separação legal de bens, comunicam-se os adquiridos na constância do casamento), editada com o intuito de interpretar o art. 259 do CC/1916, ainda na época em que cabia à Suprema Corte decidir em última instância acerca da interpretação da legislação federal, mister que hoje cabe ao Superior Tribunal de Justiça. 
4. Embargos de divergência conhecidos e providos, para dar provimento ao recurso especial. (STJ, 2018)

\subsection{EFEITOS SUCESSÓRIOS}

Por fim, passa-se à análise dos efeitos sucessórios de falecido que era casado sob o regime da separação legal para mitigar a justificativa de que este regime protegeria eventual herança.

Primeiramente, caso o de cujus tenha deixado descendentes, estes farão jus à toda herança. Entretanto, a mitigação aqui reside no fato de que haverá meação dos bens adquiridos onerosamente na constância do casamento. $\mathrm{Na}$ ausência de descendentes, o cônjuge concorre com estes na sucessão de todos os bens deixados pelo autor da herança. E não havendo herdeiros em linha reta, a sucessão será deferida por inteiro ao cônjuge supérstite.

Além disso, sempre é possível que o titular da herança disponha, por testamento, da parte disponível de seu patrimônio em prol do cônjuge, não havendo qualquer proibição para tanto, o que mitigaria a vedação do artigo 1.829 , inciso I do Código Civil:

Art. 1.829. A sucessão legítima defere-se na ordem seguinte:

I - aos descendentes, em concorrência com o cônjuge sobrevivente, salvo se casado este com o falecido no regime da comunhão universal, ou no da separação obrigatória de bens (art. 1.640, parágrafo único); ou se, no regime da comunhão parcial, o autor da herança não houver deixado bens particulares;

Desta maneira, além de tal norma se mostrar inócua e completamente destoante do ordenamento jurídico infraconstitucional, passaremos à análise à luz da Lei Maior e a incompatibilidade com esta.

\section{INCONSTITUCIONALIDADE}

Patente a discrepância do artigo do código civilista em estudo com a Carta Magna, sendo que sua inconstitucionalidade poderia ser verificada tanto em controle difuso 
quanto em concentrado realizado pela Corte Suprema, sendo o posicionamento da professora Silmara Juny Chinelato (2004).

A Constituição da República erigiu como um de seus fundamentos logo no artigo 1ㅜ, abaixo transcrito, a dignidade da pessoa humana. Logo, este princípio deve pautar a atuação do Estado, por meio de políticas públicas ou ao legislar, bem como a aplicação e interpretação das leis constituindo como verdadeiro "norte" a ser seguido.

Art. 1ำ A República Federativa do Brasil, formada pela união indissolúvel dos Estados e Municípios e do Distrito Federal, constitui-se em Estado Democrático de Direito e tem como fundamentos:

I - a soberania;

II - a cidadania;

III - a dignidade da pessoa humana;

IV - os valores sociais do trabalho e da livre iniciativa;

V - o pluralismo político.

Tal fundamento estabelece que a pessoa humana, numa visão kantiana, deve ser, sempre, tratada como a finalidade da sociedade e, por conta disso, sua dignidade está acima de qualquer discriminação, seja ela estatal ou não. Tanto este fundamento foi valorizado pelo constituinte, que o $\S 2^{\circ}$ do artigo $5^{\circ}$ da Magna Carta determina que o rol de direitos fundamentais é meramente exemplificativo e pode ser ampliado apenas pela análise dos princípios constitucionais ou pelo simples fato de o Brasil ser signatário de tratado internacional sobre direitos humanos, a saber:

Os direitos e garantias expressos nesta Constituição não excluem outros decorrentes do regime e dos princípios por ela adotados, ou dos tratados internacionais em que a República Federativa do Brasil seja parte.

Sendo assim, a dignidade da pessoa humana constitui o verdadeiro alicerce de todo o ordenamento jurídico brasileiro e, ao estabelecer que pessoas maiores de 70 (setenta) anos não teriam discernimento necessário para escolher o regime patrimonial de seu casamento, o Código Civil ofende diretamente este fundamento. 
Prosseguindo com o estudo constitucional, ressalta-se que a ofensa não ofende somente a dignidade da pessoa humana, mas também a sociedade como um todo ao fazer a distinção das famílias atingidas pela aplicação desta regra. O artigo 226 da Constituição Federal, inserido no título da Ordem Social, elege a família como a base da sociedade e, por conta disso, deve ser especialmente protegida pelo Estado, logo, não pode por este ser limitada: "A família, base da sociedade, tem especial proteção do Estado".

Além disso, mister salientar que há também uma grave ofensa ao princípio da isonomia, consagrado pelo artigo 5ํㅜ, inciso I da Constituição da República, pela distinção estabelecida aos nubentes septuagenários:

Art. 5o Todos são iguais perante a lei, sem distinção de qualquer natureza, garantindo-se aos brasileiros e aos estrangeiros residentes no País a inviolabilidade do direito à vida, à liberdade, à igualdade, à segurança e à propriedade, nos termos seguintes:

I - homens e mulheres são iguais em direitos e obrigações, nos termos desta Constituição;

Mesmo que a lei, em sentido amplo, tenha por finalidade precípua a distinção de situações merecedoras de atenção ou não, sendo próprio da lei que desigualdades sejam estabelecidas. Entretanto, deve haver pertinência e razoabilidade com o objeto da tutela legal para que esta discriminação seja considerada justa.

Ao analisar o princípio da isonomia, o eminente jurista Celso Antônio Bandeira de Mello leciona que a desigualdade é normal e não é, por si só, injusta, havendo situações em que a igualdade pura seja não seja considerada justa. Tal entendimento advém do princípio aristotélico que os desiguais sejam tratados de forma desigual na exata medida de sua desigualdade.

Desta maneira, o doutrinador estabelece critérios para que uma diferenciação normativa seja concebida de forma justa, sendo necessário que sejam conjugados cumulativamente para aferição da adequação da discriminação ao caso concreto: 
Parece-nos que o reconhecimento das diferenciações que não podem ser feitas sem quebra da isonomia se divide em três questões:

a) A primeira diz com o elemento tomado como fator de desigualação;

b) A segunda reporta-se à correlação lógica abstrata existente entre 0 fator erigido em critério de discrímen e a disparidade estabelecida no tratamento jurídico diversificado;

c) A terceira atina à consonância desta correlação lógica com os interesses absorvidos no sistema constitucional e destarte juridicizados. (MELLO, 2011, p. 48)

Por conseguinte, confrontando-se a norma em avaliação, verifica-se que o critério discriminatório de a pessoa possuir 70 (setenta) anos não guarda qualquer correlação lógica com o fato de ter que se casar, obrigatoriamente, pelo regime da separação de bens. Ainda assim, ainda que houvesse alguma correspondência racional desta distinção com o tratamento jurídico destinado a estas pessoas, não seria possível passar pelo terceiro critério vez que a constituição, como exposto acima, tem como fundamento a dignidade da pessoa humana.

\section{CONSIDERAÇÕES FINAIS}

Diante de todos os argumentos expostos não há outro desfecho senão pela completa inadequação da imposição do regime de separação de bens aos maiores de 70 (setenta) anos, constituindo em verdadeira anomalia legal. Desta maneira, tendo em vista o artigo 1.641, inciso II do Código Civil estar plenamente vigente e não havendo qualquer norma, até o momento, que o revogue expressa ou tacitamente, a inaplicabilidade deverá ser efetivada pelo Poder Judiciário no exercício da jurisdição.

Em sede de controle difuso de constitucionalidade, o magistrado, ao julgar o caso concreto, poderá deixar de aplicar a norma em tela tendo por fundamento os argumentos citados no item "6". Além disso, em consonância com a disposição do artigo $5^{\circ}$ do Lei de Introdução às normas do Direito Brasileiro (Decreto-Lei no 4.657/1942): "Na aplicação da lei, o juiz atenderá aos fins sociais a que ela se dirige e às exigências do bem comum", não há pertinência do referido dispositivo com os fins sociais ou mesmo com o bem comum. 
Por fim, perfeitamente cabível que seja proposta Ação Direta de Inconstitucionalidade no Supremo Tribunal Federal arguindo descumprimento aos artigos 1ㅇ, inciso III; $5^{\circ}$, inciso I e 226, já citados anteriormente, e, reconhecendo a incompatibilidade constitucional, a decisão seria vinculante em toda a atuação jurisdicional.

\section{REFERÊNCIAS BIBLIOGRÁFICAS}

AIDAR, Antonio Ivo. Herança do cônjuge/companheiro no regime da separação obrigatória de bens. Disponível em: $<$ https://www.anoreg.org.br/site/2019/08/26/artigo-heranca-do-conjuge-companheirono-regime-da-separacao-obrigatoria-de-bens-por-antonio-ivo-aidar/>. Acesso em: 14 out. 2019.

ALMEIDA, Silmara Juny de Abreu Chinelato e Silmara Juny de Abreu Chinelato e. Comentários ao código civil: parte especial: do direito de família, vol. 18 (artigos 1.591 a 1.710). São Paulo: Saraiva, 2004. 565 p.

BRASIL. Constituição (1988). Constituição da República Federativa do Brasil. Brasília.

. Lei no 10.406, de 10 de janeiro de 2002. Código Civil. Brasília.

GONÇALVES, Carlos Roberto. Direito civil brasileiro, volume 6: direito de família. 15. ed. São Paulo: Saraiva, 2018. 728 p.

MELLO, Celso Antônio Bandeira de. O Conteúdo Jurídico do Princípio da Igualdade. 3. São Paulo: Malheiros, 2011. 48 p.

RIO DE JANEIRO. IBGE - COORDENAÇÃO DE POPULAÇÃO E INDICADORES SOCIAIS. (Ed.). Tábua completa de mortalidade para o Brasil - 2017: breve análise da evolução da mortalidade no Brasil. Rio de Janeiro: lbge, 2018. 28 p. Disponível em: <https://biblioteca.ibge.gov.br/index.php/bibliotecacatalogo?view=detalhes\&id=2101628 >. Acesso em: 14 out. 2019. 
STJ. (30 de maio de 2018). EMBRAGOS DE DIVERGÊNCIA EM RECURSO ESPECIAL: EREsp 1623858 - MG (2016/0231884-4) . Relator: Ministro Lázaro Guimarães. DJ: 30/05/2018. Acesso em 2019, disponível em STJ: https://ww2.stj.jus.br/processo/revista/inteiroteor/?num_registro=201602318844\&dt_ publicacao=30/05/2018.

TAISSUN, Amin Seba. O regime de separação obrigatória de bens: restrições à Súmula 377 do Supremo Tribunal Federal. Rios Eletrônica: Revista Científica da FASETE, Paulo Afonso, v. 6, n. 6, p.96-105, dez. 2012.

TARTUCE, Flávio. Direito Civil, v. 5: direito de família, 14. Rio de Janeiro: Forense, 2018.

Disponível em:

<http://pergamum.mackenzie.br/biblioteca_s/minhabiblioteca.php?>. Acesso em: 14 out. 2019.

VELOSO, Zeno. Casal quer afastar súmula 377. Disponível em: <http://www.ibdfam.org.br/artigos/1201/Casal+quer+afastar+s\%C3\%BAmula+377>. Acesso em: 14 out. 2019.

Enviado: Dezembro, 2020.

Aprovado: Dezembro, 2020. 